\title{
EL BUEN VIVIR COMO DISCURSO CONTRAHEGEMÓNICO. POSTDESARROLLO, INDIGENISMO Y NATURALEZA DESDE LA VISIÓN ANDINA
}

\author{
Jorge Polo Blanco ${ }^{1}$ y Eleder Piñeiro Aguiar ${ }^{23}$ \\ ${ }^{1}$ Escuela Superior Politécnica del Litoral, Ecuador \\ ${ }^{2}$ Universidade da Coruña, España \\ ${ }^{3}$ Universidad Adolfo Ibáñez-Sede Viña, Chile
}

\section{Introducción}

"Ante la brutalidad y la falta de conciencia de la fuerza pública...". Con esas contundentes palabras empieza el comunicado emitido por la Confederación de Nacionalidades Indígenas del Ecuador (CONAIE), en respuesta al estado de excepción promulgado por el Gobierno de la República. El contexto de semejante medida fueron las intensas protestas (promovidas por los colectivos indígenas y por otros sectores de la sociedad civil) desencadenadas por los decretos de carácter neoliberal (uno más de los ya famosos "paquetazos"). En esa declaración de la confederación indígena también se hace referencia a la ocupación de los territorios ancestrales, como planes de avanzada del Gobierno Nacional (con objetivos extractivistas más o menos encubiertos) apoyados militarmente. En el mencionado texto se recuerda, además, el derecho a la autodeterminación efectiva y a la impartición autónoma de justicia, reconocidas ambas en el Tratado 169 de la OIT y en la Constitución del Ecuador. Esas medidas de corte neoliberal, en definitiva, han marcado un giro copernicano con respecto a la fase progresista precedente, no solo en el Ecuador sino en buena parte de Iberoamérica. Y, en este cambio de escenario, el indigenismo político habrá de jugar todavía un rol determinante. El movimiento indígena, en efecto, ha tenido y seguirá teniendo una importancia decisiva en la conformación sociopolítica del país andino. Los discursos tejidos en torno al "Buen vivir", objeto de estudio del presente trabajo, han contribuido notablemente a la conformación de una potente contrahegemonía.

Debemos remarcar que la noción de "Buen Vivir" no es unívoca, sino polisémica. Es, además, un término en permanente reconstrucción, repetido en más de doscientas ocasiones en el ecuatoriano Plan Nacional del Buen Vivir (Senplades 2013). Este concepto, y debemos señalarlo desde el comienzo, alberga dentro de sí una vertiente más indigenista o cultural-ancestral, una 
dimensión explícitamente ecologista y post-desarrollista, otra básicamente económica y, por último, un aspecto de intensificación democratizadora y ciudadana. También puede ser entendido como una nueva filosofía o una nueva ética. Pero lo cierto es que existen críticas radicales que lo conciben como una nueva ideología gubernamental (Domínguez y Caria 2014).

Todas estas dimensiones se vinculan entre sí, pero en ocasiones surgen fricciones y contradicciones internas muy acentuadas. En algunos casos, en lo referente a la versión indigenista y ecologista, han surgido importantes disensiones (o abiertos conflictos sociopolíticos) cuando los derechos ancestrales sobre la tierra son vulnerados por políticas económicas de carácter productivista y desarrollista (Vališková 2016: 66). En casos así, el indigenismo y su defensa de la Pachamama se veían confrontados con proyectos económicos y de política pública destinados, en última instancia, a luchar contra la pobreza (fundamentados en la obtención de recursos por parte del Estado, mediante la extracción de minerales o hidrocarburos). Ambos objetivos, defender los derechos de la naturaleza y reducir la inequidad, forman parte consustancial del "Buen Vivir", pero han aparecido en ciertos casos como incompatibles. Estaríamos ante un discurso complejo que, en ocasiones, albergaría dentro de sí elementos difícilmente conciliables. Y las discrepancias no solo tendrían que ver con ciertas colisiones entre una visión "indígena" y otra "occidental" -categorías analíticas que, en sí mismas, suponen un reduccionismo tanto conceptual como ontológico-, sino que al interior mismo de cada una de estas categorías existiría una heterogeneidad irreductible de criterios.

Según Hidalgo Flor (2012: 101) son cuatro los pilares sobre los que se asienta el discurso en cuestión, en el contexto de la región andina de inicios del Siglo XXI: a) impugnación del mercado como regulador total de la sociedad; b) demandas indígenas, centradas en sus críticas a la modernidad y a la colonialidad; c) propuestas de participación directa, esto es, democratización y aumento del poder político de los marginados; d) defensa de la soberanía nacional (o nacional-popular, para ser más exactos) ante los efectos más nocivos de la mundialización y la globalización; y además, la reacción defensiva, en este contexto, frente a la "norteamericanización" del mundo (Ritzer 1995; Echeverría 2008). Es, bajo esta constelación de sentidos, que el Buen Vivir "puede ser recuperado como ejemplo concreto de la construcción de una contrahegemonía" (Hidalgo Flor y Márquez Fernández 2012: 102). Se trata de un discurso que, a pesar de sus contradicciones internas, alberga un indubitable pulso impugnador del orden existente; impugnador en lo político-económico y en lo jurídico, pero también en lo subjetivo, en lo moral y en lo cultural. Es en este punto cuando cobra relevancia la concep- 
tualización indígena en lo referente a qué se entiende por poder y cómo son las relaciones de poder, y las posibles impugnaciones a la matriz colonial que de tales concepciones se derivan. Otra cuestión será, por supuesto, evaluar hasta qué punto dicha impugnación ha podido avanzar desde lo discursivo hacia las transformaciones reales. Y, por otro lado, no hemos dejado de observar una recurrente y oportunista instrumentalización del "problema indígena" (Gellner 1994).

A lo largo de las siguientes páginas expondremos las conexiones polémicas que el Buen Vivir, en tanto que construcción político-discursiva, ha mantenido con los modelos extractivistas, desarrollistas y neoliberales. Nos centraremos en los aportes indígenas a esta discusión, principalmente en su relación con el ambientalismo. En el apartado final, y tras generar una reflexión sobre la epistemología eurocéntrica, enfatizaremos que la perspectiva crítica andina sirve para pensar de una forma decolonial. Tras lo cual, expondremos unas conclusiones a modo de resumen de los apartados antedichos, los cuales inician con las ideas y nociones desarrolladas a partir del Sumak Kawsay quechua en el Ecuador, incluido en el texto constitucional de 2008.

\section{Una alternativa al desarrollismo, al productivismo y al neoliberalismo}

La noción Buen vivir emergió con potencia en el vocabulario político de algunos países hispanoamericanos que experimentaron importantes procesos de transformación social y económica en la primera década del siglo XXI. Dicha noción cobró una relevancia notabilísima a través del reconocimiento obtenido en las Asambleas constituyentes de Ecuador (sumak kawsay, en lengua quichua) y Bolivia (suma qamaña, en lengua aymara), aprobadas entre 2008 y 2009 (Belotti 2014). Estas expresiones pretendían hacer referencia a ciertos elementos societarios y axiológicos anclados en los modos de vida que existieron (y en cierto modo todavía subsisten) en las relaciones comunitarias de los pueblos indígenas (andinos y amazónicos), cuyas cosmovisiones tienen raíces milenarias. Unos términos que acabaron integrándose, como elementos galvanizadores cruciales, en algunas propuestas políticas transformadoras y en algunos discursos de signo emancipador. Tan es así, que incluso terminarían cristalizando (o al menos eso han pretendido sus detentadores) como un pensamiento pretendidamente alternativo al desarrollismo capitalista occidental (Vega 2014; Piñeiro 2016a). Los movimientos indigenistas, ecologistas y políticos surgidos a principios del siglo XXI, en la región latinoamericana, tuvieron en su punto de mira y en su horizonte crítico todo ese largo periodo que media desde el desarrollismo iniciado por 
el presidente norteamericano Truman (véase su discurso inaugural de 1949), que luego se prolongará hasta la denominada "larga noche neoliberal", esto es, hasta las décadas de los 80 y los 90 del pasado siglo.

Como señalaba Catherine Walsh (2009), los nuevos textos constitucionales, parcialmente inspirados en esas cosmovisiones andinas y amazónicas (también afrodescendientes, pero en menor medida), intentaron constituir una ruptura económica, cultural e incluso espiritual con los modelos propios de la modernidad colonialista, eurocéntrica y neoliberal. Históricamente, las constituciones de Ecuador se habían guiado por criterios eurocéntricos ligados a los intereses de las élites criollas, por lo cual la de Montecristi (2008) supuso una importante ruptura con esa inercia secular. Es cierto, quizás, que hubo en este proyecto una vocación "utópica", como así lo reconocen algunos de sus propios artífices (Acosta 2011b); sin embargo, sí se obtuvieron efectivas transformaciones simbólicas, culturales y materiales. Dicho hiato trató de implementarse desde la planificación pública, tal y como expone el Plan de Desarrollo del Buen Vivir ecuatoriano, cuando consigna que "en el Ecuador hemos rescatado la planificación para no duplicar esfuerzos y evitar el desperdicio de recursos, que tanto nos retrasó en la época del neoliberalismo" (Senplades 2013). Acompañando críticamente dicha planificación, que pretendía salirse de las lógicas hegemónicas del mercado, el movimiento indígena presionó para que las políticas públicas adquiriesen, por fin, un cariz más en concordancia con sus intereses, históricamente obliterados.

De esta manera, la incorporación del sumak kawsay o buen vivir representa un hito trascendental [...] Al proponer una filosofía de bienestar radicalmente opuesta al bienestar neoliberal, este último con su centro en el individuo y en un individualismo alienante de posesión -el "tener", que se mencionó anteriormente-, y caracterizado por la falta de articulación social, la nueva Constitución Política asume la responsabilidad y necesidad de terminar con el modelo neoliberal, pero también de comprometerse con la tarea histórica de re-fundar el Estado y la sociedad de manera jamás considerada en casi doscientos años de vida republicana" (Walsh 2009: 228).

Una enmienda a los modelos de desarrollo dominantes que el discurso del Buen Vivir comparte con otros modelos contrahegemónicos, tales como puedan ser el Índice de Felicidad Humana elaborado en Costa Rica, el Índice de Felicidad de Bután e incluso otros paradigmas de "desarrollo humano" no reduccionistas y no economicistas elaborados en los países del Norte, siendo las propuestas de Amartya Sen y Joseph Stiglitz (2013) en la Francia de Sarkozy el mejor ejemplo de ello (Boltaina 2012). El Buen Vivir, en ese sentido, quiso inspirar prácticas públicas y modelos socioeconómicos 
que rompiesen con la "moderna mercantilización del mundo" (Polo 2017). Y, por supuesto, trató de "medir" el desarrollo de una manera alternativa a los modelos más econométricamente reduccionistas (Phélan 2011). Porque la "calidad de vida" del mundo indígena no puede ser "medida" con los mismos parámetros que se utilizan para una urbe occidentalizada, puesto que ciertos elementos esenciales para dichas comunidades (la preservación y revalorización de la identidad cultural o la implementación de una educación intercultural, por ejemplo) no quedan reflejados en los índices estandarizados. Esta circunstancia ha podido ser estudiada en Doce experiencias de desarrollo indígena en América Latina (Carrasco, Iturralde y Uquilla 2003), en Informe sobre desarrollo humano de los pueblos indígenas de México (Gálvez y Lemaresquier 2006) y en el estudio Desenvolvimiento humano e as desigualdades étnicas no Brasil. Um retrato de final de século (Paixão 2000).

El Buen Vivir, empleado de una forma maximalista, pretendió erigir una nueva concepción del mundo que pudiese articularse desde "la visión de los marginados de la historia" (Acosta 2011a: 62), desde los Damnés (Fanon 1999), desde la óptica de los oprimidos (Freire 2005) o desde los subalternos, esto es, desde esos "sujetos que no ocupan una posición" (Spivak 2003).

Sumak Kawsay y Suma Qamaña tienen, pues, importancia en primer lugar en el terreno simbólico: los que fueron marginados por conquistadores y criollos aportan ahora desde su visión del mundo palabras que pretenden colaborar con la solución de los problemas creados por aquellos. Y, en segundo lugar, porque señalan dónde han podido estar los errores del llamado desarrollo (Tortosa 2011a: 5).

Esto último aparece muy emparentado con las propuestas de la "filosofía de la liberación" de Dussel (1985) o Scannone (1990), pero también se puede pensar que existirían conexiones con la Teología de la Liberación y su "opción preferencial por los pobres" (Ellacuría 2012). La humanización-descolonización era el eje del proyecto, en este sentido. Romper con inveteradas asimetrías (materiales, pero también epistémicas), elaborar nuevas gramáticas de sociabilidad y dar voz a los sin voz (por ellos mismos y desde ellos mismos; no desde la visión del amo). Esto es, que los secularmente silenciados adquieran, por sí mismos, un lugar de enunciación.

El avance hacia una "ecología de saberes" se dio ya en el momento constituyente del discurso del Buen Vivir, por cuanto se trata de un "reconocimiento de la pluralidad de conocimientos heterogéneos [que] se fundamenta en la idea de que el conocimiento es interconocimiento" (Sousa Santos 2010a: 49), privilegiando la interactividad sobre la unilateralidad y proponiendo una suerte de convivencia dialogante e intercambiadora (no 
jerárquica) entre quienes pretenden poseer el único conocimiento científico válido y aquellos sectores de la población o aquellas culturas que poseen otro tipo de conocimientos o saberes (populares, ancestrales, no-occidentales). Boaventura de Sousa Santos señala que las ciencias sociales hegemónicas han sido excesivamente "monoculturales", es decir, han hundido sus raíces solo en el saber propio de la cultura occidental. La "ecología de saberes", por el contrario, resalta que existe una enorme variedad de conocimientos a lo largo y ancho del mundo y parte, además, de un presupuesto que el canon epistemológico eurocéntrico nunca estuvo dispuesto a admitir: los distintos saberes pueden coexistir en simetría, sin necesidad de que unos aplasten, ridiculicen o silencien a los otros. El Buen Vivir engarzaría completamente con esta misma perspectiva, pues resulta pertinente a la hora de criticar la presunta jerarquía epistémica de los "expertos" y tecnócratas, adalides del progreso y demiurgos del desarrollo (Esteva 2009: 2).

La Constitución vigente en el Ecuador desde 2008 explicita que la naturaleza tiene derechos intrínsecos; es éste un caso único a nivel mundial, pues no se trata únicamente de que los seres humanos tengan derecho a un medio ambiente saludable (concepto todavía encuadrado en un esquema antropocéntrico), sino de que la naturaleza tiene ella misma derechos (concepto, ahora sí, biocéntrico). Pero, más allá de enunciar estos derechos, debieran incluirse las obligaciones que la humanidad tiene hacia la naturaleza, aspecto éste no recogido en el texto constitucional. Debemos resaltar que, por vez primera en el recorrido constitucionalista del Ecuador, en toda la época republicana, el sustento ideológico y axiológico no está anclado exclusivamente en paradigmas eurocéntricos (Cortez 2010: 2). En la Constitución de Montecristi se deja constancia de una cuestión perentoria, por lo tanto: una simple "reforma verde" del capitalismo, que no entre a discutir su concepto esencialmente mercantilizador de los "recursos naturales", tampoco tiene demasiado recorrido (Gudynas 2011). En este sentido, se contradicen y deslegitiman -en lo discursivo- los modelos de desarrollo hegemónicos en las últimas décadas del siglo XX, a saber, la gobernanza neoliberal y el paradigma desarrollista-extractivista. Según Esteva (2009: 7) "el desarrollo es hoy el emblema de un mito en agonía", a lo que el mismo autor agrega que el experimento de hace más de cuatro décadas no ha sido solamente irresponsable, sino también un fracaso. Por todo ello, la cuestión decisiva del medio ambiente -la destrucción depredadora e irreversible de los ecosistemas- habría de ocupar un lugar preponderante e inaplazable en cualquier agenda política que pretendiese ser mínimamente emancipadora. Los discursos basados en el Buen Vivir asumieron e integraron esa problemática. 
Pero no se puede perder de vista, por otro lado, que "el buen vivir no se limita a las condiciones económicas, políticas, socioculturales y ambientales, sino que también involucra y pone en consideración condiciones epistémicas", puesto que "pretende poner en práctica y asumir con seriedad filosofías de vida que rompen radicalmente con el marco filosófico-político que orienta el Estado y la sociedad neoliberal" (Walsh 2009: 230). Reestablecer y reconstruir una cierta "comunión" entre la naturaleza y las personas sería un acto liberador y, además, profundamente descolonizador. ¿̇n qué sentido? Porque quebrantaría una específica lógica de poder y desestabilizaría una cierta epistemología dominante, basadas ambas en el dominio explotador de la naturaleza (y de otros seres humanos). En cualquier caso, esa escisión hombre-naturaleza sólo podrá restañarse-siquiera sea parcialmente-a través de un proceso descolonizador que abandone los esquemas económicos y culturales más perjudiciales de la cosmovisión occidental. "El «sumak kawsay» de las poblaciones indígenas es un tipo de «ética» que entiende la política en función de una relación fundamental respecto a la naturaleza" (Cortez 2010: 6), y cuya base estaría en la reconstrucción de relaciones armónicas, equitativas e interdependientes entre seres y naturaleza. Por estos motivos, los textos constitucionales (y los planes de desarrollo subsecuentes), parcialmente inspirados en el Buen Vivir, tienen -o han pretendido tener- un alcance refundador, esto es, una capacidad de propiciar o posibilitar un salto más allá de (y por fuera de) la modernidad colonial y capitalista. Con -o desde- el Buen Vivir se aspiró a erigir una nueva forma de vida que, siendo nueva, se inspirase no obstante en lo tradicional y en lo ancestral. Y haciendo mucho hincapié en la racionalidad solidaria (no competitiva y no productivista), lo cierto es que esos discursos sí coadyuvaron a socavar el dominante imaginario del "desarrollo" (Marañón 2014).

Las élites criollas y mestizas, que desde siempre comandaron la construcción de los Estados-nación iberoamericanos, pensaron en todo momento que dentro de sus países existía un componente atávico y refractario al progreso; se trataba de una rémora cultural que obstaculizaba de manera persistente los impulsos modernizadores y que, como cabía esperar, se identificaba con lo indígena (Hoselitz 1960; Lewis 1965). Esa visión, ya presente en la teoría de las "etapas del crecimiento económico" (Rostow 1993) planteaba un estadio decisivo de despegue económico (o take off) donde las culturas ancestrales se consideraban un lastre. Y, bajo el paraguas de semejante paradigma, las iniciativas impulsadas por los poderes públicos se encaminaban preferentemente a la estimulación de la "modernización" de las comunidades "atrasadas", promoviendo su "integración" en la sociedad nacional mediante la educación/ alfabetización. Se consideraba que dichas dinámicas de aculturación eran 
condición sine qua non para el desarrollo tecnoeconómico de la República. Fruto de estos planteamientos "integradores" fue, por ejemplo, la Misión Andina del Ecuador (entre 1954 y 1972), la intervención más ambiciosa y tecnocrática de cuantas se implementaron en esa época en el medio indígena y campesino de este país (Solo de Zaldívar 2013).

La ideología decimonónica del "progreso" (que colapsará en los campos de concentración) y ulteriormente la ideología del "desarrollo" (tras la Segunda Guerra Mundial), cimentaron una visión del mundo altamente productivista y tecnocrática (Chuji 2014). En las cosmovisiones indígenas, y es ésta una notable diferencia, no aparece la concepción de un "proceso lineal" que establezca un estado "anterior" y otro "posterior" (Acosta 2010: 11). El discurso que emana del Sumak Kawsay quiere erigirse, justamente, en una visión alternativa de lo que significa el verdadero desarrollo social y humano. Y ya no tanto en la sofisticación teórica de cierta intelectualidad indigenista (teorizaciones que siempre conservan regustos eurocéntricos, a pesar de su perspectiva crítica), sino en las propias formas de vida de muchísimas comunidades indígenas de América Latina podemos hallar elementos de resistencia ante esos programas de homogeneización étnico-cultural (que, naturalmente, persiguen nada más que una "rentabilización" de sus tierras). El pueblo Wiwa que habita la Sierra Nevada de Santa Marta (Colombia), en ese sentido, ha venido oponiéndose al sometimiento de su territorio al fetiche del "desarrollo" (Fajardo y Gamboa 1998). Porque la "tierra" no es para ellos una mercancía o algo que les "pertenezca" (en un sentido de propiedad moderno y occidental); muy al contrario, son ellos los que -bajo unas coordenadas holísticas- pertenecen a la tierra, tal y como expone Miguel Bartolomé refiriéndose a las comunidades guaraníes de la Triple Frontera (Argentina, Paraguay, Brasil): "El espacio no se circunscribe a la tierra, sino que básicamente incluye a la selva, y no puede ser entendido como una propiedad, sino como un ámbito destinado a ser habitado y respetado, porque está vivo y tiene sus propios intereses; los seres humanos son pobladores, predadores, comensales y partícipes de la selva, pero no sus dueños" (Bartolomé 2009: 248).

No es el territorio, en definitiva, un objeto externo al cual exprimir y domeñar desde un punto de vista puramente económico y tecnológico, sino un lugar saturado de significación (memoria de los ancestros, por ejemplo) y en el cual se hallan integrados en armonía con todo lo vivo que hay en él. Semejante cosmovisión ofrece, en sí misma, una resistencia (más o menos exitosa, pero aun así resistencia) ante los procesos de mercantilización desarrollista que quieren imponerse de forma coactiva. Incluso la espiritualidad y la religiosidad han servido como diques de contención frente a la occidentalización que viene imponiéndose desde los tiempos de la Colonia, 
como puede verse en las comunidades mbyá (subgrupo guaraní) en el actual Paraguay (Piñeiro 2016b).

\section{La vertiente indigenista}

Resulta precisa y acertada la apreciación de Alberto Acosta (2010: 13), cuando señala que "la visión andina no es la única fuente de inspiración para impulsar el Buen Vivir", pues "se sustenta también en algunos principios filosóficos universales: aristotélicos, marxistas, ecológicos, feministas, cooperativistas, humanistas". Pero, aun con ello, hemos de reconocer el papel de vanguardia que han jugado los movimientos indígenas andinos en la elaboración de la propuesta, superando viejos paradigmas (aunque incorporando de ellos algunos elementos valiosos), y colocando en el punto de mira aspectos como el equilibrio, la armonía, la cooperación, la reciprocidad, la sustentabilidad o la equidad. El Buen Vivir fungiría como contrapunto epistemológico y cultural a la racionalidad productivista y economicista. Y más allá del articulado constitucional, en el caso ecuatoriano, el Buen Vivir (que no debe solaparse con el "bienestar occidental") puede ser entendido como la construcción colectiva de una nueva forma de vida. No se trata simplemente de elevar la calidad de vida de la población, en ocasiones confundida con un reduccionismo económico centrado en el consumo (o, más precisamente, en el consumismo). Por lo tanto, los cambios jurídicos y estatales deben ir acompañados de una profunda transformación cultural.

El concepto de "equilibrio" es clave en este imaginario indígena, pues las relaciones entre el mundo espiritual, el material y el simbólico son el centro de las normas comunales y de la supervivencia de la cultura, algo que se pretende trasladar al total del entramado estatal. Asumiendo los postulados del Sumak Kawsay, por lo tanto, se podría avanzar hacia la impugnación de los modelos de desarrollo importados desde las potencias occidentales altamente industrializadas, que iniciados en la Guerra Fría han llevado más bien al "maldesarrollo" de millones de personas y cientos de pueblos en todo el mundo (Tortosa 2011b).

La racionalidad occidental siempre vivió instalada en una radical escisión hombre-naturaleza, siendo así que esta última aparecía siempre como un objeto externo al que dominar y explotar de forma ilimitada. De la naturaleza, así concebida, había de extraerse el máximo rendimiento posible, sea cual sea el costo humano y ambiental.

Para empezar a enfrentar este añejo mensaje, sostenido en un divorcio profundo de la economía y la Naturaleza, hay que rescatar las verdaderas dimensiones 
de la sustentabilidad. Esta exige una nueva ética para organizar la vida misma. Se precisa reconocer los límites biofísicos de las actividades desarrolladas por los humanos. La realidad nos demuestra hasta la saciedad que la Naturaleza tiene límites. Y esos límites, aceleradamente alcanzados por los estilos de vida antropocéntricos, particularmente exacerbados por las demandas de acumulación del capital, son cada vez más notables e insostenibles (Acosta 2010: 18).

El Buen Vivir, enfrentándose a esta crucial problemática, pretende erigir una economía más solidaria y menos depredadora, no tan encuadrada en las pautas economicistas de la pura competitividad individualista. Sin embargo, debemos considerar que las comunidades indígenas y campesinas andinas aparecen, en algunos de estos discursos, idealizadas y esencializadas. Encontramos relatos que operan como fabulaciones ahistóricas y folclorizadas, puesto que en ellos aquellas sociedades fulgen como una suerte de entidades puras, esto es, como "supervivencias" precolombinas inmaculadas. En esos relatos mistificadores tales comunidades aparecen enteramente regidas por principios sociales de reciprocidad y, por lo tanto, como si fuesen comunidades estacionarias y esencialmente "anti-mercado" y "anti-desarrollo" (una retórica que, es verdad, no deja de recordar al mito del "buen salvaje", que popularizara entre otros Jean-Jacques Rousseau). Semejante perspectiva la podemos encontrar en Javier Medina (2001: 176) o en Atawallpa Oviedo (2012), toda vez que ambos han sostenido que las comunidades amerindias son sociedades básicamente anti-mercantiles que habrían resistido durante quinientos años, en una suerte de inmaculado reducto geográfico e histórico, los embates de la aculturación desarrollista occidental. Todo lo cual es muy paradójico, puesto que la idea de los "indios puros", pegados a la naturaleza en un estado prístino, inmaculado e incontaminado, forma parte de ese imaginario colonial que gravita en la relación de Occidente con sus Otros. Ante esta versión mistificada y reduccionista, la propuesta consistiría en comprender las relaciones de alteridad, diversidad e interculturalidad en toda su complejidad y heterogeneidad, no ya desde lógicas individualistas, multiculturalistas y ni tan siquiera mestizas, todavía presas de la monocultura occidental (Walsh 2012: 24). Según Marisol de la Cadena (2008: 87-89), el concepto de "hibridez mestiza", ensalzado y prestigiado por las élites ilustradas criollas, ocultaba en realidad un claro programa de aculturación, hasta el punto de que tal vez fuera necesario "rescatar a los mestizos del mestizaje".

Partiendo de un sustrato cultural preexistente, la intelectualidad del mundo indígena boliviano y ecuatoriano (principalmente) cumplió un papel determinante en la reelaboración y codificación de la noción "Buen Vivir". Mediante dicha labor, tal concepto se encaminó hacia su consolidación 
epistemológica y, finalmente, se proyectó dentro de un discurso político alternativo y contrahegemónico (Hidalgo-Capitán, Arias y Ávila 2014). Pero debe señalarse, y no es éste un detalle menor, que en tal construcción discursiva también participaron abundantemente intelectuales no indígenas. Algunos autores inclusive han señalado que esta noción de Buen Vivir es un neologismo construido ad hoc por cierta intelectualidad indígena (y no indígena, como decíamos), hasta el punto de que resulta difícil encontrar referencias a la misma en la abundantísima literatura etnográfica sobre comunidades andinas anterior al cambio de milenio (Viola Recasens 2014: 63). Buena parte de dicha literatura alberga, según sostienen sus críticos, muchas falencias en lo referente a una contextualización adecuada y fundamentada en información empírica rigurosa. Podría llegar a sostenerse, incluso, que nos hallamos ante una "tradición inventada" (Hobsbawm y Ranger 2002). Y, por otro lado, todos estos discursos (convertidos muy a menudo en ideología oficialista gubernamental) han promovido una progresiva homogenización de la verdadera diversidad indígena bajo la máscara artificial de un inexistente "indígena ideal" (Pérez-Gañán 2017).

A pesar de todas estas salvedades y críticas, lo cierto es que el universo semántico que gira en torno a la idea del Buen Vivir ha operado pragmáticamente a la hora de tejer un discurso y una práctica política específica, más allá de su eventual preexistencia histórica y etnográfica. El concepto, por ende, ha sido determinante a la hora de construir una identidad política nueva y a la hora de forjar un nuevo sujeto colectivo y, por esto mismo, también ha funcionado y operado en buena medida como uno de esos "significantes vacíos" de los que hablaba Ernesto Laclau (2013). En efecto, no ha importado tanto la verdad del discurso (esto es, no ha sido tan decisivo el hecho de corroborar la preexistencia efectiva del Buen Vivir en los modos de vida realmente existentes de las comunidades andinas y amazónicas) cuanto la operatividad pragmática de dicho concepto a la hora de aglutinar fuerzas sociales en principio dispersas e inconexas; el Buen vivir, más allá de su correlato empírico, ha funcionado como un articulador político-discursivo de primer orden. En ese sentido, la elaboración intelectual e ideológica del concepto ha perseguido la estipulación y afianzamiento de un nuevo cuerpo de derechos fundamentales plasmados en los nuevos textos constitucionales que, a su vez, pretendían informar y orientar en buena medida (aunque no sin contradicciones) las políticas públicas (Manosalvas 2014).

Por otro lado, hemos de constatar que en muchas ocasiones el "pachamamismo" y el indigenismo militante (que, en teoría, manejan un discurso marcado por la "anti-modernidad" y el "anti-occidentalismo") se han retroalimentado, no obstante, con ciertos procesos de la globalización capi- 
talista que promueven ese turismo destinado a occidentales hambrientos de "primitivismo"; esos "blancos" que se muestran ávidos por experimentar la adrenalina mística que creen hallar en el contacto con la alteridad cultural (Gascón 2009). Algo que, paradójicamente, también sirve para que las comunidades indígenas sobrevivan, así sea pagando el precio de una importante aculturación: turismo indigenista o "turismo comunitario", que conllevan una cierta mercantilización de la propia identidad cultural (Comaroff y Comaroff 2011). Un proceso semejante ha podido estudiarse entre los ticuna del Alto Amazonas, involucrados en esas dinámicas contradictorias (Ullán de la Rosa 2000). En el caso australiano, tal y como muestra Povinelli (2002), el "aborigen" emerge como una figura sobre la que se proyectan ciertas ansiedades multiculturales e importantes dosis de culpa melancólica (lamentos por la "autenticidad" perdida y diezmada), todo ello tamizado por una indisimulada folklorización.

En realidad, muchas comunidades y nacionalidades indígenas se readaptaron y rearticularon en el espacio de los márgenes, unas veces identificándose o relacionándose (por estrategia o por necesidad ineluctable) con el entramado político del Estado (también con la economía capitalista) y con el entramado simbólico-cultural de la modernidad europea, y en otras ocasiones alejándose de todo ello para situarse en una posición de cierta exterioridad. Tal dialéctica de interioridad/exterioridad, ese saber vivir en la frontera porosa y conflictiva de "dos mundos" (impactando en la esfera estatal/republicana, para obtener reconocimientos jurídicos y gozar de los mismos derechos y prestaciones que el resto de "ciudadanos"; y al mismo tiempo replegándose en la fortificación de espacios comunitarios autónomos parcialmente ajenos a lo estatal/republicano), este tipo de situaciones, decíamos, pueden observarse en las comunidades tarahumaras (o rarámuris) del norte de México (Loera González 2013 y 2015). En definitiva, esta ubicación en los márgenes permite a las comunidades adoptar un enfoque estratégico para hacer frente a las vulnerabilidades socioeconómicas, reforzando su poder negociador con el Estado y su capacidad de autogestión política (siendo conscientes, eso sí, de la inevitabilidad de ciertas dosis de aculturación y pérdida de "idiosincrasia").

El kume mogñen del pueblo Mapuche es una expresión análoga al sumaq kawsay (quechua), al suma qamaña (aymara) y al ñande reko (guaraní). También en este caso hallamos un modo de vida y una cosmovisión que, de diferentes modos, ponen en cuestión las concepciones occidentales fundadas en el crecimiento económico insostenible, la acumulación infinita y la explotación depredadora de los recursos naturales. En el caso Mapuche, por lo demás, esas fricciones entre los modos de vida comuni- 
tarios y los modelos desarrollistas que, desde el siglo XIX, se han querido imponer con violencia en sus territorios ancestrales, esas fricciones con el Estado, decíamos, han devenido en un descarnado conflicto político cuya intensidad, en ocasiones, ha adquirido tintes "guerracivilistas". En este caso, la preservación de la identidad cultural se encuentra muy ensamblada con las exigencias de autonomía político-administrativa (Saavedra 2002; Hernández 2003; Marimán et. al. 2006). La "cuestión Mapuche", en ese sentido, siempre tiene una presencia significativa en la conflictividad política chilena, incluso cuando los ciclos de lucha social no tienen que ver estrictamente con la problemática indígena, como es el caso de las fortísimas movilizaciones anti-neoliberales que convulsionaron el país en noviembre de 2019 (con tristes episodios de vulneración de los derechos humanos por parte de las fuerzas del orden).

Por supuesto, dentro de este horizonte de sentido se enmarca la ineludible cuestión del "pluralismo jurídico". En la última década del siglo XX pudo constatarse una tendencia en las reformas constitucionales emprendidas por los países que conforman la Comunidad Andina de Naciones: Colombia, Perú, Bolivia, Ecuador y Venezuela. Tales países, que en 1989 también habían ratificado el Convenio 169 de la Organización Internacional del Trabajo (OIT) sobre Pueblos Indígenas y Tribales en Países Independientes, trataron de levantar un nuevo marco jurídico caracterizado por el reconocimiento del carácter plurinacional, multiétnico e intercultural de las Repúblicas, enmarcadas hasta entonces en los parámetros excesivamente monolíticos y homogeneizadores del Estado-nación criollo y mestizo. Tales procesos, a su vez, desembocaron en el reconocimiento de los derechos de los pueblos indígenas originarios, obteniendo resultados globales, como por ejemplo la Declaración de las Naciones Unidas sobre los Derechos de los Pueblos Indígenas (aprobada por la Asamblea General mediante la resolución A/RES/61/295, del 10 de diciembre de 2007). Y, de forma subsecuente, condujeron al reconocimiento de un derecho indígena poseedor de una jurisdicción especial. Se trataba, en suma, de tener derecho al propio derecho $\mathrm{y}$, en última instancia, a la hora de avanzar en esa dirección, de lo que se consiga avanzar en una reforma de las estructuras estatales y de los entramados ideológicos que durante mucho tiempo se han sostenido en dichas estructuras. Pues, en efecto, los pueblos indígenas vivieron o subsistieron durante muchísimo tiempo en una geografía jurídica mestiza, que los excluía por definición (y con violencia) también en un plano jurídico.

La "emergencia indígena", debemos enfatizarlo, no puede entenderse sin esa dimensión jurídica (Bengoa 2000). Porque es cierto, y bien da cuenta de ello Alcida Rita Ramos, que el sintagma "ciudadanía común" ha sido 
empleado en demasiadas ocasiones para obliterar y subalternizar otras "nacionalidades" no reconocidas siquiera legalmente, aplastadas bajo el peso de una homogeneizadora ciudadanía única (1997 y 2007). Porque tras el velo de la universalidad, ya lo sabemos desde hace tiempo, se han escondido oprobiosas relaciones de dominio que fueron subyugando en lo material y en lo simbólico a múltiples nacionalidades étnicas (Ribeiro 1970); múltiples construcciones discursivas y simbólicas que, desde luego, siempre han desencadenado poderosos efectos materiales. Hablamos, en suma, de procesos que se enmarcan en una matriz de auténtico terrorismo semiótico, valga la expresión. Por ejemplo, cuando se emplea el término "indio" para reducir y laminar con esa sola etiqueta la abigarrada especificidad y la enorme variedad de pueblos americanos aborígenes, convirtiendo a éstos en una sola masa indiferenciada y explotable (Stavenhagen 1988: 14 y 43).

Lo central en estas transformaciones constitucionales es, en primer lugar, el reconocimiento de los pueblos indígenas como sujetos políticos agentes y de pleno derecho, y no ya como meros objetos de ciertas políticas públicas proteccionistas o compensatorias. Lo cual, antes que nada, implicaría un derecho a controlar de forma autónoma las propias instituciones (Salgado 2002). Pero, si el Estado ya no encarna una nación homogénea y una sola identidad cultural, de forma necesaria la dimensión jurídica también adquirirá una nueva fisionomía y un nuevo estatuto. "Al cuestionarse el monopolio de la producción jurídica por el Estado, se admiten diversos grados de pluralismo legal, reconociéndose a los pueblos y comunidades indígenas/campesinas el derecho de tener su propio derecho, autoridades y formas de justicia" (Yrigoyen 2004: 173). Tales comunidades son reconocidas como capaces de albergar sus propias instancias de producción de normas. Y si se reconoce la existencia de instituciones jurídicas propias, con plena y autónoma potestad, se debe reconocer la validez de su aplicación y la legitimidad de su ejecución (incluso si ésta conlleva algún tipo de violencia punitiva). El discurso del Buen Vivir, en este aspecto, también ha contribuido de forma decisiva a poner en la agenda pública esta cuestión largamente pendiente: reconocer la existencia de "derechos colectivos" y "consuetudinario-comunitarios" en el interior de los Estados (Stavenhagen 2010). Todo esto conllevaría un replanteamiento de la noción de "pueblo" no bajo las cartografías del Estado-nación occidental surgido en la época de las revoluciones burguesas e industrial, sino bajo otros componentes que quiebren la triada monolítica soberanía-territorio-población. El llamado indígena nos muestra que ni todo pueblo tiene un Estado, ni todo Estado pertenece a un pueblo; también nos enseña que no existe un único modo de defender la soberanía, a lo que se suma romper con las fronteras (administrativas, 
geográficas y simbólicas) definitorias de lo que Occidente entiende como Estado. El Buen Vivir nos brinda un cierto ensanchamiento de las formas de entender la democracia, pues se puede comprender la ciudadanía de muy diversos modos (Young 1990). Es, en este sentido, la lucha por el reconocimiento jurídico y por la autodeterminación socioeconómica (las tensiones territoriales y administrativas que se dan entre lo comunitario y lo estatal, valdría decir) uno de los ejes medulares del Buen Vivir andino.

\section{Respuesta a un problema medioambiental que es en realidad una crisis civilizatoria}

El problema ambiental, que deviene ya de la crisis civilizatoria, hunde sus raíces en el tipo de racionalidad que pone en juego la cultura occidental (Leff 2004). La "muerte entrópica del planeta" es el resultado de un determinado modo de ser y de estar en el mundo que, a la postre, ha resultado ser suicida. Con ello, se evidencia la radical inviabilidad de los modelos vigentes de producción y consumo (Falconí 2014). En la región latinoamericana el desarrollo (o, más bien, el desarrollismo) siempre estuvo íntimamente vinculado a la apropiación intensa y depredadora de los recursos naturales; y se ha de señalar, por lo demás, que el extractivismo económico siempre vino acompañado (e incluso posibilitado) por ciertas formas de "extractivismo epistémico" (Grosfoguel 2016). En el Ecuador, el texto constitucional de Montecristi (vigente desde 2008, recordémoslo), puso en juego un significativo viraje hacia conceptos de desarrollo más sustentables o sostenibles. Bien es verdad que hay nociones débiles de sustentabilidad, que apenas conciben una amortiguación de los efectos más nocivos sobre el medio ambiente, pero sin poner en cuestión la noción misma de "crecimiento económico ilimitado" y sin combatir frontalmente el concepto de naturaleza como recurso infinitamente explotable. Un concepto fuerte de sustentabilidad, por el contrario, sí pondría en entredicho esas nociones. El Buen Vivir, en su vertiente más radicalmente indigenista y pachamamista, maneja sin duda un concepto muy fuerte de sustentabilidad.

Nótese una vez más, pues se trata de un elemento clave y diferencial, que en el texto constitucional ecuatoriano no solo aparecen derechos humanos de tercera generación, toda vez que existe una intencionalidad muy clara por avanzar hacia una justicia ambiental que incluya no solamente el derecho de los seres humanos a un medio ambiente saludable, sino también los derechos intrínsecos de la Naturaleza, de la Pachamama, más allá de las utilidades que ésta pueda reportar a la especie humana. "Darle derechos 
a la Pachamama, de este modo, no solo es una expresión ambientalista; la Pachamama es una presencia diferente que altera fundamentalmente el sentido del desarrollo y del estado" (Escobar 2010: 310). Esto último escapa a las nociones occidentales. En ese sentido, el texto avanza mucho más que el boliviano (el cual permanece anclado en posiciones todavía utilitaristas o neo-extractivistas). Y es verdad que la Constitución ecuatoriana no renuncia a la eficiencia económica, pero siempre dentro de los límites biofísicos sustentables (y no moviliza, por lo tanto, una "eficiencia" presidida por la lógica de la máxima rentabilidad a cualquier precio). Es así que, profundizando en la estrecha conexión entre medio, sociedad, naturaleza y política, "los derechos de la naturaleza necesitan y a la vez originan otro tipo de definición de ciudadanía, que se construye en lo social pero también en lo ambiental. Este tipo de ciudadanías es plural, ya que depende de las historias y de los ambientes, y acoge criterios de justicia ecológica que superan la visión tradicional de justicia" (Acosta 2010: 20).

Si bien hay autores que exponen que los frentes de batalla contra los avances del capitalismo depredador se hallan en otros lugares, no es menos verdad que frente a los valores ( $y$, por supuesto, frente a la institucionalidad que los sustenta) del productivismo desaforado, la máxima competitividad y el egoísmo de las sociedades capitalistas, que promueven -o determinan-que los individuos se instrumentalicen entre sí en un contexto de sociabilidad mermada y debilitada, frente a todo ese universo, un nuevo pacto de convivencia inspirado en el Buen Vivir habría de implicar una transmutación de dichos valores, una metamorfosis honda de semejantes pautas psicosociales, imbricando dicha noción con propuestas ecologistas, republicanas e incluso socialistas (Ramírez 2010). Pudiéramos estar parcialmente de acuerdo en que la lucha por los derechos de la naturaleza o la lucha contra la pobreza no son más que estratagemas o batallas imaginarias que el "nuevo espíritu del capitalismo" (Boltanski y Chiapello 1999, cit. en Sánchez Parga, 2011: 32) promueve de forma maquiavélica, para diluir así un enfrentamiento más frontal y anti-sistémico contra su propia reproducción. Pero también hemos de responder que toda alternativa a la hegemonía del mercado y del sistema neoliberal es, además de perentoria, no necesariamente utópica; y, cuando menos, reconoce problemas y ofrece soluciones.

Acosta recalcaba en otro trabajo que esta noción surgió en "la periferia social de la periferia mundial" (2011a: 61), aspecto que reviste una especial importancia; porque semejante concepción, en efecto, surge al calor de las luchas populares y, en especial, de las luchas indígenas. Y quiere ser, antes que un mero reconocimiento constitucional, una nueva forma de vida que suponga una alternativa a los conceptos de "desarrollo" y "progreso" hasta 
ahora hegemónicos, esto es, un desarrollo más "hospitalario" (Esteva 2009), toda vez que dicha hegemonía fue impuesta no sin buenas dosis de violencia material y simbólica a lo largo y ancho de toda Latinoamérica.

\section{¿Acaso solo Occidente sabe pensar?}

Josef Estermann (2006: 10) señalaba que uno de los últimos coletazos ofrecidos por el eurocentrismo secular ha consistido en aseverar, de forma apriorista y dogmática, que más allá de la tradición filosófica occidental no puede haber un verdadero pensamiento. Utilizando terminología de raigambre platónica, podría decirse que sólo la tradición filosófica judeo-cristiana y grecorromana ha producido auténtica episteme, mientras que en el resto de culturas y civilizaciones que han poblado y pueblan el planeta apenas existiría una balbuciente doxa (esto es, mera charlatanería supersticiosa y pre-lógica). Como decía Aimé Césaire con ardiente y cáustico sarcasmo, "sólo Occidente sabe pensar" (2006: 37). Ante un periodo histórico, la modernidad europea (o eurocentrada), cuya cultura aparecía vertebrada casi toda ella por una episteme nuclearmente cartesiana, se tornaría imprescindible el aporte crítico de esa perspectiva epistemológica "cesariana", valdría decir, según la cual los binarismos sujeto-objeto, mente-cuerpo, cultura-naturaleza, entre otros muchos, debieran ser superados a través de una deslegitimación o impugnación de la superioridad absoluta de los primeros elementos sobre los segundos. Es así que Spivak (2003) responde con un rotundo no, argumentando que el subalterno tiene negada la capacidad de hablar, si bien hay autores desde la colonialidad que afirman que ante dicha negativa lo que se debe es avanzar hacia unas ciencias no cartesianas sino "cesarianas", siendo así que lo que éstas plantean "es nada menos que un nuevo giro en el pensamiento filosófico predominante; pero un giro como ninguno otro: un giro de-colonial" (Maldonado-Torres 2007: 159). Esto implica no tanto refutar las condiciones de racionalidad del denominado conocimiento "experto" sino "hacer ver sus pretensiones coloniales e imperiales y disputar su posicionamiento como única" (Walsh 2007: 104).

Desde el punto de vista eurocéntrico, fuera de Occidente existirían, si acaso, "cosmovisiones", término que en muchas ocasiones es empleado como subterfugio para no decir de forma explícita "pensamiento inauténtico" o "pensamiento irracional". Esos "pensamientos" extra-occidentales, como ya pretendiera establecer Lévy-Bruhl (1972) en la década de los veinte del siglo XX (es decir, ni siquiera ya en un marco decimonónico), se hallarían dominados todavía por una "mentalidad primitiva" incapaz de operar 
con categorías intelectuales verdaderamente lógicas. "Según este criterio eurocéntrico, en América Latina (pero también en África y Asia) no puede (a priori) haber existido una «filosofía» hasta el momento en que la filosofía occidental (que se concibe como la única «estricta») pisara tierra en estas partes «bárbaras» del globo terráqueo" (Estermann 2006: 23). La cultura occidental, como parte de su dominio económico-político, se arroga el papel de única portadora no de una filosofía, sino de la filosofía. Solamente Europa habría generado un pensamiento con validez atemporal y universal; el resto de los pueblos, a lo largo y ancho del planeta, apenas habrían sido capaces de producir "sabidurías particularistas", ancladas en lo local, y por ello mismo desprovistas de un estatuto epistémico verdaderamente racional. En este sentido, el proyecto del Buen Vivir entra en relación y diálogo con autores poscoloniales y decoloniales que exponen acerca de la necesidad de "provincializar Europa" (Chakrabarty 2008) o de entenderla, también per se, como "bárbara" (Galcerán 2016), por cuanto es necesaria una hermenéutica de los sujetos y de la historia para entender las múltiples modernidades que pudieron haber existido, siendo la europea-occidental sólo una de tantas.

Se debe destacar, en íntima relación con lo anterior, que siempre existió una vinculación estrechísima entre "modernidad eurocéntrica" y "blanquitud", como bien ha señalado Bolívar Echeverría (2010). Se consolidó un imaginario, enmarcado en poderosos dispositivos de jerarquización-subalternización, en el que lo "auténticamente civilizado" incluía entre sus determinaciones esenciales el pertenecer de alguna manera a la "raza blanca" y, consecuentemente, relegaba al ámbito de lo infrahumano a todos los individuos y comunidades que fueran "de color" o "no blancas", precisamente porque esa ausencia de "blanquitud" los hundía necesariamente en los abismos evolutivos de lo pre-moderno o lo primitivo (Sousa Santos 2010b). En esa matriz temporal, solo Europa había alcanzado un estadio de auténtica civilización; debía concluirse, por consiguiente, que sólo Europa sabía pensar. Pero el discurso del Buen Vivir también irrumpió para impugnar estos esquemas, que no son sino una manifestación más de esa "colonialidad del saber" que ha operado en América Latina (y otros muchos lugares del mundo) desde hace cientos de años. "Para poder aproximarse al fenómeno y tema de la «filosofía andina», es preciso romper con el eurocentrismo y occidentalismo (u occidentocentrismo) implícitos en la misma definición y delimitación de lo que se considera «pensamiento filosófico» o "filosofía» a secas". (Estermann 2006: 11). Porque esa "violencia epistémica" de la que hablaba Homi K. Bhabha (2002: 63), ejercida a través de la mirada del hombre blanco que construye al Otro, también se manifiesta en esa cláusula que declara que sólo los occidentales son aptos para desarrollar un verdadero pensamiento filosófico. 


\section{Etnografiando el Buen Vivir}

El Buen Vivir, tal y como lo hemos venido caracterizando, ha tenido implantación operatoria y pragmática en buena parte del mundo indígena latinoamericano. Se ha podido estudiar con detalle, por ejemplo, cómo esta noción ha estado presente en las organizaciones del sector cooperativo indígena de la provincia del Azuay, en Ecuador (Endara 2014). Y aunque, en ciertas ocasiones, el Buen Vivir no aparezca teorizado o mencionado explícitamente, se halla presente igualmente en la praxis viva de muchas comunidades; tal es el caso de ciertas comunidades de Chiapas, en el sur de México, donde un trabajo de campo ha podido verificar que en múltiples ámbitos de la vida cotidiana se manejan criterios (de acción y reflexión) perfectamente subsumibles en la semántica del Buen Vivir (Santana 2015). Porque, si bien es cierto que los estudios sobre el Buen Vivir han tenido su epicentro en el mundo andino y amazónico, su presencia también puede rastrearse en otras latitudes. Por ejemplo, entre los tzeltales o tseltales, el grupo étnico más grande ubicado en una región montañosa localizada en Chiapas, es uno de los muchos grupos étnicos que descienden de los mayas, conservando una lengua que pertenece a la rama del grupo lingüístico de esta misma cultura. El pueblo tzeltal sostiene que al Lekil Kuxlejal, que puede traducirse por "Vida Buena", no se llega de forma inercial o espontánea, sino que requiere una trabajosa instauración mediante la deliberada acción del hombre en las diferentes facetas de su vida, en las distintas formas de actuar y hablar: en el matrimonio, labrando el mutuo respeto entre mujer y hombre; con los hijos, estableciendo relaciones de consideración y confianza; con el buen desempeño en el trabajo; en las fiestas que hace la comunidad, con el aseo de la casa, etc. La Lekil Kuxlejal se encuentra presente en la praxis cotidiana, a pesar de que ésta se vea afectada por otras dinámicas exógenas y "modernizantes". Sentimiento de pertenencia, tradición y compromiso grupal, autonomía y soberanía territorial, integración con el mundo natural o compromiso ético con la cohesión comunitaria, todos estos elementos, en definitiva, conforman la "Vida Buena" o Lekil Kuxlejal, en estas comunidades mayas (Paoli 2003).

Cabría enfatizar que es en los territorios, más que en los textos escritos por intelectuales indígenas o indigenistas que viven en las grandes urbes, donde puede observarse una implantación viva del Buen Vivir, practicado en la cotidiana relación con el mundo natural y en los vínculos que sostienen el tejido comunitario. El Sumak Kawsay, en ese sentido, fue uno de los discursos que permitió al movimiento indígena y a otras organizaciones sociales enfrentar el neoliberalismo de forma efectiva (Lang y Mokrani 2011). El levantamiento indígena acontecido en el Ecuador, en octubre de 
2019, es un buen ejemplo. Reaccionando (junto a otros sectores del país, principalmente el gremio del transporte) a un "paquetazo" económico decretado por el gobierno de la República (y "decidido" por el FMI), en donde medidas neoliberales y de recortes del gasto social afectan a poblaciones subalternas de todo el país; las organizaciones indígenas de todo el país se movilizaron hacia Quito. Ya en la capital se sucedieron los duros enfrentamientos con la policía, asaltaron y tomaron temporalmente el edificio de la Asamblea Nacional e intentaron lo mismo con el palacio presidencial. El gobierno ecuatoriano, incluso, hubo de trasladar su sede a Guayaquil, ante la intensidad de las protestas. Las comunidades afro secundan las protestas indígenas, acontecimiento que refrenda nuestra lectura del Sumak Kawsay como factor de cambio y elemento de disputa contrahegemónica (eminentemente indígena, pero no exclusivo de este colectivo) frente al "progreso" eurocéntrico y frente al desarrollismo depredador de lo común puesto en marcha una y otra vez por el neoliberalismo. Si se leen los comunicados de la Confederación de Nacionalidades Indígenas del Ecuador (CONAIE) o del Movimiento Indígena y Campesino de Cotopaxi (MICC), podrá comprobarse que en ellos están presentes algunas de las nociones vinculadas al Buen Vivir. El gobierno del Ecuador, finalmente, retiró el decreto.

Sin embargo, en el mes de noviembre de ese mismo 2019, otro terremoto político sacudió la geografía andina: Evo Morales, primer presidente indígena del continente, cayó tras los que muchos han denominado "golpe de Estado" (con decenas de muertos en las calles, buena parte de cuales eran indígenas, asesinados por la Policía y el Ejército). Sin entrar en un balance pormenorizado de lo que supuso el gobierno de Evo, y más allá de sus insuficiencias y contradicciones, lo cierto es que el Estado se transformó en "plurinacional" bajo su mandato, y el nuevo texto constitucional estuvo muy atravesado por el suma qamaña, el "Buen Vivir" aymara. Con la traumática y violenta caída del gobierno del MAS, y a la luz del discurso puesto en juego por las nuevas autoridades del país (que habrán de convocar un nuevo proceso electoral, con Evo exiliado en México), observamos en Bolivia un inquietante retorno de ideas "monoculturales" (con ciertos tintes de fundamentalismo cristiano) y un palpable revanchismo anti-indigenista.

Es así que, desde lo local, el Sumak Kawsay ofrece aliento y discurso para la resistencia. Lo ancestral, de tal modo, permanece conectado a las luchas globales. Los estilos de vida de los pueblos originarios de América, que han practicado por siglos (no de manera "pura", sino mimetizándose dialécticamente con la "exterioridad" que ha tratado siempre de integrarlos y asimilarlos, tal como mostraba Marisol de la Cadena más arriba), esas formas de vida, decíamos, han servido de plataforma o baluarte a la hora de tejer 
resistencias (Scott 2004) frente a los recurrentes intentos de devastación de su territorio. Las luchas contra la megaminería abierta, tan presentes en la conflictividad social latinoamericana (Alimonda 2011), son un ejemplo paradigmático de la defensa indígena del territorio; en tales momentos álgidos pueden observarse, de manera nítida y palmaria, muchos de los componentes que conforman eso que se ha venido denominando Buen Vivir. En el caso concreto del Ecuador, las protestas indígenas encabezaron las protestas contra el extractivismo llevado a cabo por la multinacional Chevron en la Amazonía (Ceceña y Ornelas 2017; Polo y Piñeiro 2019: 206).

El caso de Sarayaku, en el Ecuador, es otro buen ejemplo de resistencia indígena y defensa del territorio. La parroquia Sarayaku, situada en la provincia de Pastaza, es un pueblo kichwa de poco más de mil habitantes, con una economía de agricultura comunitaria, recolección, caza y pesca. La resistencia de Sarayaku en contra del extractivismo petrolero es emblemática, pues durante lustros este pueblo indígena ha defendido su modo de vida tradicional. En 1992 ingresó la petrolera argentina CGC, con una exploración sísmica muy agresiva, trazando una zona de exclusión para los habitantes de Sarayaku en su propio territorio. Con ello, quedaban muy limitados sus mecanismos sociales de subsistencia, con la consecuente afectación de la soberanía alimentaria y la vulneración de derechos a la libre circulación y el acceso a territorios sagrados. En 1993 dio comienzo la exploración petrolera del llamado "Bloque 23", sin consulta previa a las comunidades kichwas amazónicas, pese afectar al 60\% de sus territorios. Desde entonces, se sucedieron las luchas. Ya en 2002, por ejemplo, la Asamblea de Sarayaku resolvió impedir el ingreso de cualquier empresa en su territorio, y se creó el Frente de la Unidad de la nacionalidad kichwa de Pastaza. 2003 fue un año de confrontación explícita y agudización del conflicto, hasta el punto de que las Fuerzas Armadas intervienen para proteger los campamentos petroleros de CGC en territorio Sarayaku. Después de un largo proceso de litigios y peleas sociales, en 2012 la Corte Interamericana dicta sentencia definitiva a favor de Sarayaku, en la que se obliga al Estado a indemnizar a esta comunidad y se le insta, asimismo, a ofrecer disculpas al pueblo por la violación a los derechos humanos cometidos durante la operación petrolera en el Bloque 23. Además, la sentencia obligaba al Estado ecuatoriano a remediar el daño ambiental causado y sentaba un importante precedente para que el Estado tuviera, a partir de entonces, el deber de realizar consultas a todas aquellas comunidades que fueran a quedar afectadas por algún proyecto extractivo (estos mecanismos de consulta, por cierto, quedaron consagrados en la Constitución ecuatoriana de 2008; un texto constitucional atravesado, precisamente, por el discurso del Buen Vivir). 
El Sumak Kawsay exige habitar un territorio sin contaminación, una tierra limpia que asegure la soberanía alimentaria de la comunidad; supone una economía sustentable que no distorsione el equilibrio del entorno natural y requiere, asimismo, poder practicar los conocimientos ancestrales, manteniendo las prácticas tradicionales y las costumbres. Para el pueblo Sarayaku el territorio es Kawsak Sacha, "Selva Viviente", un espacio vital destinado a ubicar el sustento físico y espiritual de los miembros de la comunidad; un territorio que es vida, alimento, salud, sacralidad e identidad. Todo lo que conforma el Kawsak Sacha está entrelazado, relacionado o vinculado. Y ahí, en esa lucha contra el extractivismo petrolero, podemos observar cómo la defensa de un modo de vida tenía que ver con la autonomía territorial, sí, pero también con el sostenimiento de los saberes ancestrales del sacha runa yachay (conocimientos de los hombres de la selva) y el aseguramiento del sumak allpa (tierra fértil sin mal). Se trató, en suma, de un ejercicio vivo y real del Sumak Kawsay (Rodríguez Salazar 2016: 315-322).

\section{A modo de conclusión}

El Sumak Kawsay, en definitiva, permitiría construir una alternativa epistémica (y ético-política) al discurso ortodoxo de la teoría económica convencional, una línea de fuga capaz de salir de los límites establecidos por ese paradigma dominante.

En las comunidades indígenas no existen individuos que maximizan su comportamiento en función de su egoísmo estratégico. Ese mismo principio de racionalidad estratégica que calcula el mayor beneficio posible de recursos escasos, no tiene ni sentido ni pertinencia en el mundo andino ni en ningún otro estructurado desde las instituciones ancestrales (Dávalos 2011: 28).

Su sola presencia, la subsistencia de formas de vida situadas fuera (o al menos parcialmente fuera) de la racionalidad capitalista, pone en cuestión el núcleo ideológico del discurso económico dominante: la supuesta perennidad ahistórica de la lógica económica basada en el individualismo competitivo y en la maximización permanente de la propia ganancia (Acosta 2013). Es por eso que el Sumak Kawsay anclado en los saberes y en las prácticas culturales de estos pueblos puede erigirse en un locus epistémico desde el cual deconstruir todo el armazón conceptual (e ideológico) del discurso económico ortodoxo. Por ello, este Buen Vivir permite pensar otro tipo de subjetividades, más allá del moderno y eurocéntrico Homo oeconomicus (Mill 1994 [1836]). Y, por lo mismo, puede también erigirse 
en un horizonte de sentido que al menos permita imaginar alternativas a la modernización capitalista.

Todavía está por verse si el Buen Vivir modificará de verdad los imaginarios y las prácticas de lo que hemos venido entendiendo por "desarrollo". Como es lógico, con la simple inserción del Buen Vivir en la Constitución y en los planes nacionales de actuación pública no se superarán automáticamente las desigualdades ni los efectos perversos del desarrollismo precedente, pues una cosa es el plano discursivo-normativo y otra muy diferente su efectiva implementación. Pero es, al menos, un relevante acuerdo de mínimos sobre el que trabajar con el fin de conjugar lo ético, lo político, lo público y lo común en proyectos que, en último término, intenten trabajar en aras de la emancipación de las mayorías sociales históricamente excluidas.

Recebido em: 27 de abri de 2019

Aprovado em: 02 de janeiro de 2020

\section{Jorge Polo Blanco}

Doctor en Filosofía por la Universidad Complutense de Madrid (España), actualmente trabaja como docente e investigador en la Escuela Superior Politécnica del Litoral (Ecuador). Sus principales líneas de investigación son teoría decolonial, filosofía política, justicia indígena, extractivismo y derechos de la naturaleza, populismo, feminismo o economía política. Ha publicado múltiples artículos en revistas académicas especializadas, y tres libros: Anti-Nietzsche. La crueldad de lo político (2020), La economía tiránica. Sociedad mercantilizada, dictadura financiera y soberanía popular (2015) y Perfiles posmodernos. Algunas derivas del pensamiento contemporáneo (2010).

http://orcid.org/0000-0001-9415-5406

Correo institucional: polo@espol.edu.ec

Correo personal: hiperbolik1983@hotmail.com

\section{Eleder Piñeiro Aguiar}

Doctor en Antropología Social y Cultural por la Universidade da Coruña (España). Actualmente trabaja como docente e investigador en la Facultad de Sociología de la Universidade da Coruña, y como investigador asociado externo de la Universidad Adolfo Ibáñez, sede Viña del Mar (Chile). Sus principales áreas de investigación son la movilidad humana, el indigenismo, la teoría del Estado y el pensamiento crítico latinoamericano. Está a cargo de la subdirección de la Revista Latina de Sociología y de la dirección de la revista Dominio de las Ciencias.

http://orcid.org/0000-0001-6770-7180

Correo institucional: eleder.pineiro.aguiar@udc.es

Correo personal: elederpa1983@gmail.com 


\section{Referencias bibliográficas}

ACOSTA, Alberto. 2010. El Buen Vivir en el camino del post-desarrollo. Una lectura desde la Constitución de Montecristi. Quito: Fundación Friedrich Ebert, FES-ILDIS.

—_. 2011a. "El Buen Vivir en el camino del post-desarrollo. Algunas reflexiones al andar". En: G. Weber (Eds.), Debates sobre cooperación y modelos de desarrollo. Perspectivas desde la Sociedad Civil en el Ecuador. Quito: Centro de Investigaciones Ciudad, Observatorio de la Cooperación al Desarrollo en Ecuador, pp. 61-82.

—. 2011b. "El Buen (con) Vivir, una utopía por (re) construir. Alcances de la Constitución de Montecristi". OBETS. Revista de Ciencias Sociales, Vol. 6, No 1: 35-67.

_. 2013. El Buen vivir. Sumak Kawsay, una oportunidad para imaginar otros mundos. Barcelona: Icaria.

ALIMONDA, Héctor (Coord.). 2011. La Naturaleza colonizada. Ecología política y minería en América Latina. Buenos Aires: CLACSO-CICCUS.

BARTOLOMÉ, Miguel Alberto. 2009. Parientes de la selva. Los guaraníes Mbyá de la Argentina. Paraguay: CEADUC.

BELOTTI, Francesca. 2014. "Entre bien común y buen vivir. Afinidades a distancia". Íconos. Revista de Ciencias Sociales, FLACSO, Quito, No 48: 41-54.

BENGOA, José. 2000. La emergencia indígena en América Latina. México: Fondo de Cultura Económica.

BHABHA, Homi K. 2002. El lugar de la cultura. Buenos Aires: Manantial.

BOLTAINA, Xavier. 2012. "Bhutan i el "Gros National Happiness»". L'Erol: revista cultural del Berguedà, 114: 7-10.
CARRASCO, Tania; ITURRALDE, Diego; UQUILLAS, Jorge Enrique (Coord.). 2003. Doce experiencias de desarrollo indígena en América Latina. La Paz: Ediciones Abya-Yala.

CECEÑA, Ana Esther.; ORNELAS, Raúl (Coord.). 2017. Chevron. Paradigma de la catástrofe civilizatoria. México: Siglo XXI.

CÉSAIRE, Aimé. 2006. Discurso sobre el colonialismo. Madrid: Akal.

CHAKRABARTY, Dipesh. 2008. Al margen de Europa. Pensamiento poscolonial y diferencia histórica. Barcelona: Tusquets.

CHUJI, Mónica. 2014. "Modernidad, desarrollo, interculturalidad y Sumak Kawsay o Buen Vivir". En: A. L. Hidalgo-Capitán, A. Guillén A y N. Deleg (Eds.), Antología del Pensamiento Indigenista Ecuatoriano sobre el Sumak Kawsay. Huelva (España) y Cuenca (Ecuador): CIM, FIUCUHU, PYDLOS, Centro de Investigación en Migraciones (CIM), Universidad de Huelva, Universidad de Cuenca, pp. 155-158.

COMAROFF Jean; COMAROFF, John L. 2011. Etnicidad S. A. Buenos Aires, Madrid: Katz.

CORTEZ, David. 2010. "Genealogía del Buen Vivir en la nueva Constitución ecuatoriana". En: R. Fornet-Betancourt (Hg.), Gutes Leben als humanisiertes Leben. Vorstellungen vom guten Leben in den Kulturen und ihre Bedeutung für Politik und Gesellschaft heute. Dokumentation des VIII. Internationalen Kongresses für Interkulturelle Philosophie. Denktraditionen im Dialog. Studien zur Befreung und Interkulturalität, Band 30. Wissenschaftsverlag Main, pp. 227-248. 
DÁVALOS, Pablo. 2011. "El Sumak Kawsay (Buen Vivir) y la crítica a la teoría económica como ideología". Polémika. Revista del Instituto de Economía de la Universidad San Francisco de Quito, Año 3, No 7: 17-31.

DE LA CADENA, Marisol. 2008. "¿Son los mestizos híbridos?". En: M. de la Cadena (Eds.), Formaciones de indianidad. Articulaciones raciales, mestizaje y nación en América Latina. Popayán, Colombia: Envión.

DOMÍNGUEZ, Rafael; CARIA, Sara. 2014. "La ideología del Buen Vivir: la metamorfosis de una "alternativa al desarrollo" en desarrollo de toda la vida". Pre-textos para el debate, Universidad Andina Simón Bolívar, $\mathrm{N}^{\circ} 2$ :

DUSSEL, Enrique. 1985. Filosofía de la liberación. Buenos Aires: La Aurora. ECHEVERRÍA, Bolívar. 2010. Modernidad y blanquitud. México: Era. . 2008. La americanización de la modernidad. México: UNAM, Dirección General de Publicaciones y Fomento Editorial.

ELLACURÍA, Ignacio. 2012. La lucha por la justicia. Selección de textos de Ignacio Ellacuría (1969-1989). Bilbao, España: Universidad de Deusto.

ENDARA, Sebastián. 2014. "Organización para el Buen Vivir. Estudio de caso de organizaciones del sector cooperativo en la provincia del Azuay (Ecuador) y sus aportes al Buen Vivir de las poblaciones y sus territorios". OBETS. Revista de Ciencias Sociales, Vol. 9, No 1: 95-137.

ESCOBAR, Arturo. 2010. Una minga para el postdesarrollo. Lugar, medio ambiente y movimientos sociales en las transformaciones globales. Lima: Programa Democracia y Transformación Global Universidad Nacional Mayor de San Marcos, Facultad de Ciencias Sociales.
ESTERMANN, Josef. 2006. Filosofía andina. Sabiduría indígena para un mundo nuevo. La Paz: Instituto Superior Ecuménico Andino de Teología.

ESTEVA, Gustavo. 2009. "Más allá del desarrollo: la buena vida". Cuadernos de Trabajo Sobre el Desarrollo, $\mathrm{N}^{\circ}$ 4: 7-18.

FAJARDO, Luis Alfonso; GAMBOA, Juan Carlos. 1998. Multiculturalismo y derechos humanos: una perspectiva desde el pueblo indígena Wiwa de la Sierra Nevada de Santa Marta. Bogotá: ESAP.

FALCONÍ, Fander. 2014. Al sur de las decisiones. Enfrentando la crisis del siglo XXI. Quito: El Conejo.

FANON, Frantz. 1999. Los condenados de la tierra. México: Txalaparta.

FREIRE, Paulo. 2005. Pedagogía del oprimido. Madrid: Siglo XXI.

GALCERÁN, Montserrat. 2016. La bárbara Europa. Una mirada desde el postcolonialismo y la descolonialidad. Madrid: Traficantes de Sueños.

GÁLVEZ, Xóchitl; LEMARESQUIER, Thierry. 2006. Informe sobre desarrollo humano de los pueblos indígenas de México 2006. México: CDI-PNUD.

GASCÓN, Jordi. 2009. El turismo en la cooperación internacional. De las brigadas internacionalistas al turismo solidario. Barcelona: Icaria. GELLNER, Ernest, J. 1994. El arado, la espada y el libro. La estructura de la historia humana. Barcelona: Península.

GROSFOGUEL, Ramón. 2016. “Del «extractivismo económico» al «extractivismo epistémico»y al «extractivismo ontológico»: una forma destructiva de conocer, ser y estar en el mundo". Tabula Rasa, No 24: 123-143. 
GUDYNAS, Eduardo. 2011. "Desarrollo, Derechos de la Naturaleza y Buen Vivir después de Montecristi". En: G. Weber (Eds.), Debates sobre cooperación y modelos de desarrollo. Perspectivas desde la Sociedad Civil en el Ecuador. Quito: Centro de Investigaciones CIUDAD, Observatorio de la Cooperación al Desarrollo en Ecuador, pp. 83-102.

HERNÁNDEZ Isabel. 2003. Autonomía o ciudadanía incompleta. El pueblo Mapuche en Chile y Argentina. Santiago, Chile: CEPAL, PEHUEN. HIDALGO-CAPITÁN, Antonio Luis; ARIAS, Alexander; ÁVILA, J Javier. 2014. "El pensamiento indigenista ecuatoriano sobre el Sumak Kawsay". En: A. L. Hidalgo-Capitán, A. Guillén y N. Deleg (Eds.), Antología del Pensamiento Indigenista Ecuatoriano sobre el Sumak Kawsay. Huelva, España; Cuenca, Ecuador: CIM, FIUCUHU, PYDLOS, Centro de Investigación en Migraciones (CIM), Universidad de Huelva, Universidad de Cuenca, pp. 29-73.

HIDALGO FLOR, Francisco; MÁRQUEZ FERNÁNDEZ, Álvaro (Eds.). 2012. Contrahegemonía y Buen Vivir. Quito: Universidad Central del Ecuador.

HOBSBAWM, Eric; RANGER, Terence (Eds.). 2002. La invención de la tradición. Barcelona: Crítica.

HOSELITZ, Bert Frank. 1960. Sociological aspects of economic growth. Chicago: Free Press.

LACLAU, Ernesto. 2013. La razón populista. México: Fondo de Cultura Económica.

LANG, Miriam; MOKRANI, Dunia (Comp.). 2011. Más allá del desarrollo. Grupo Permanente de Trabajo sobre Alternativas al Desarrollo. Quito: Fundación Rosa Luxemburgo, Ediciones Abya Yala.
LEFF, Enrique. 2004. Racionalidad ambiental. La reapropiación social de la naturaleza. México: Siglo Veintiuno. LÉVY-BRUHL, Lucien. 1972. La mentalidad primitiva. Buenos Aires: La Pléyade.

LEWIS, W. Arthur. 1965. "Sobre planeación en los países atrasados". En La planeación económica. Ciudad de México: Fondo de Cultura Económica, pp. 136-144.

LOERA GONZÁLEZ, Juan Jaime. 2013. Conflicting paths to wellbeing. Raramuri and mestizo inter-ethnic relations in northern Mexico. Tesis Doctoral en Estudios del Desarrollo, Universidad de Sussex, Reino Unido.

——. 2015. "La construcción de los buenos vivires; entre los márgenes y tensiones ontológicas". Polis. Revista Latinoamericana, Volumen 14, $\mathrm{N}^{\mathrm{o}}$ 40: 101-121.

MALDONADO-TORRES, Nelson. 2007. "Sobre la colonialidad del ser: contribuciones al desarrollo de un concepto". En: N. Maldonado-Torres y R. Grosfoguel (Eds.), El giro decolonial. Reflexiones para una diversidad epistémica más allá del capitalismo global. Bogotá: Siglo del Hombre Editores, pp. 127-167.

MANOSALVAS, Margarita. 2014. "Buen vivir o sumak kawsay. En busca de nuevos referenciales para la acción pública en Ecuador". Íconos. Revista de Ciencias Sociales, ${ }^{\circ}$ 49: 101-121.

MARAÑÓN, Boris (Coord.). 2014. Buen Vivir y descolonialidad. Crítica al desarrollo y la racionalidad instrumentales. México: Universidad Nacional Autónoma de México, Instituto de Investigaciones Económicas.

MARIMÁN, Pablo (et. al.). 2006. iEscucha, winka! Cuatro ensayos de Historia Nacional Mapuche y un 
epílogo sobre el futuro. Santiago, Chile: LOM.

MEDINA, Javier. 2001. Suma Qamaña. La comprensión indígena de la Vida Buena. La Paz: GTZ-PADEP.

MILL, John Stuart. 1994 [1848]. "On the definition and method of political economy". En: D. Hausman (Ed.), The Philosophy of Economics. An anthology. Cambridge: Cambridge University Press, pp. 52-68.

OVIEDO, Atawallpa. 2012. ¿Qué es el Sumak Kawsay? La Paz: Sumak Editores.

PAIXÃO, Marcelo. 2000. "Desenvolvimento humano e as desigualdades étnicas no Brasil. Um retrato de final de século". Revista Proposta, Rio de Janeiro, $\mathrm{N}^{\circ}$ 86: 30-52.

PAOLI, Antonio. 2003. Educación, autonomía y lekil kuxlejal. Aproximaciones sociolingüísticas a la sabiduría de los tseltales. México: Universidad Autónoma Metropolitana.

PÉREZ-GAÑÁN, Rocío. 2017. "Mecanismos de exclusión de los pueblos originarios en los discursos y representaciones del Buen Vivir ecuatoriano y el Vivir Bien boliviano: el tutelaje y la desapropiación simbólica". Revista Iberoamericana de Estudios de Desarrollo, Volumen 6, № 2: 48-70.

PHÉLAN, Mauricio. 2011. "Revisión de índices e indicadores de desarrollo. Aportes para la medición del Buen Vivir (Sumak Kawsay)". OBETS. Revista de Ciencias Sociales, Vol. 6, $\mathrm{N}^{\circ}$ 1: 69-95.

PIÑEIRO AGUIAR, Eleder. 2016a. "Radicalidad y crítica del Buen Vivir. Una lectura desde Bolívar Echeverría". Economía y Desarrollo, Vol. 157, $\mathrm{N}^{\circ}$ 2: 120-129.

——. 2016b. "Palabra-alma-nombre. Espiritualidad guaraní como acto de resistencia". Revista San Gregorio, $\mathrm{N}^{\circ}$ 13: 20-29.
POLO BLANCO, Jorge. 2017. "Contrafiguras de la moderna mercantilización del mundo. Aristóteles, Karl Polanyi y el Sumak Kawsay". Éndoxa. Series filosóficas, $\mathrm{N}^{\circ} 40$ : 203-230

POLO BLANCO, Jorge; PIÑEIRO, Eleder. 2019. "Ciencia moderna, planeta torturado. Una reflexión crítica sobre el modo eurocéntrico de conocer la naturaleza e intervenir en el medio ambiente". Revista Izquierdas, Vol. 46: 194-217.

POVINELLI, Elizabeth A. 2002. The Cunning of Recognition. Indigenous Alterities and the Making of Australian Multiculturalism. Durham, USA: Duke University Press.

RAMÍREZ, René. 2010. "Socialismo del sumak kawsay o biosocialismo republicano". En: Los nuevos retos de América Latina. Socialismo y Sumak Kawsay. Quito: SENPLADES, pp. 55-76.

RAMOS, Alcida Rita. 1997. "Convivência interétnica no Brasil. Os índios e a nação brasileira". Série Antropologia, $\mathrm{N}^{\circ} 221$.

. 2007. "El indio contra el Estado". En: M. L. Lagos y P. Calla (Comp.), Cuaderno de Futuro $N^{\circ}$ 23. Antropología del Estado. Dominación y prácticas contestatarias en América Latina. La Paz: INDH/ Programa de las Naciones Unidas para el Desarrollo, pp. 238-284.

RIBEIRO, Darcy. 1970. Os índios e a civilização. Rio de Janeiro: Civilização Brasileira.

RITZER, George. 1995. La Mcdonalización del mundo. Un análisis de la racionalización de la vida cotidiana. Barcelona: Ariel.

RODRÍGUEZ SALAZAR, Adriana. 2016. Teoría y práctica del Buen Vivir. Orígenes, debates conceptuales y conflictos sociales. El caso de 
Ecuador. Tesis Doctoral, Universidad del País Vasco, España.

ROSTOW, Walt Whitman. 1993. Las etapas del crecimiento económico. Un manifiesto no comunista. Madrid: Ministerio de Trabajo y Seguridad Social.

SAAVEDRA, Alejandro. 2002. Los Mapuche en la sociedad chilena actual. Santiago, Chile: LOM, Universidad Austral.

SALGADO, Judith. (Comp.). 2002. Justicia indígena. Aportes para un debate. Quito: Universidad Andina Simón Bolívar, Abya-Yala.

SÁNCHEZ PARGA, José. 2011. "Discursos retrovolucionarios: Sumak Kawsay, derechos de la naturaleza y otros pachamamismos". Ecuador Debate, $\mathrm{N}^{\circ}$ 84: 31-50.

SANTANA, María Eugenia. 2015. "El buen vivir, miradas desde dentro". Revista Pueblos y Fronteras Digital, Vol. 10, N 19: 171-198.

SCANNONE, Juan Carlos. 1990. Nuevo punto de partida en la filosofía latinoamericana. Buenos Aires: Guadalupe.

SCOTT, James C. 2004. Los dominados y el arte de la resistencia. México: Era.

SENPLADES. 2013. Plan Nacional de Desarrollo/Plan Nacional para el Buen Vivir 2013-2017. Quito: SENPLADES.

SOLO DE ZALDÍVAR, Víctor Bretón. 2013. "Etnicidad, desarrollo y 'Buen Vivir'. Reflexiones críticas en perspectiva histórica". European Review of Latin American and Caribbean Studies, N 95: 71-95.

SOUSA SANTOS, Boaventura. 2010a. Descolonizar el saber. Reinventar el poder. Montevideo: Trilce.

—_. 2010b. Para descolonizar Occidente. Más allá del pensamiento abismal. Buenos Aires: Consejo Latinoamericano de Ciencias Sociales-CLACSO: Prometeo.
SPIVAK, Gayatri. 2003. "iPuede hablar el subalterno?". Revista colombiana de antropología, 39: 297-364.

STAVENHAGEN, Rodolfo. 1988. Derecho indígena y derechos humanos en América Latina. México: Instituto Interamericano de Derechos Humanos, El Colegio de México.

- 2010. Los pueblos originarios: el debate necesario. Buenos Aires: CTA Ediciones, CLACSO.

STIGLITZ, Joseph E.; SEN, Amartya.; FITOUSSI, Jean-Paul. 2013. Medir nuestras vidas. Las limitaciones del PIB como indicador de progreso: el informe de la comisión sobre la medición de las actividades económicas y el progreso social. Barcelona: RBA.

TORTOSA, José María. 2011a. Sumak kawsay, suma qamaña, buen vivir. Madrid: Fundación Carolina.

——. (Comp.). 2011b. Maldesarrollo y mal vivir. Pobreza y violencia a escala mundial. Quito: Abya-Yala.

ULLÁN DE LA ROSA, Francisco Javier. 2000. "Los indios ticuna del Alto Amazonas ante los procesos actuales de cambio cultural y globalización". Revista Española de Antropología Americana, No 30: 291-336.

VALIŠKOVÁ, Barbara. 2016. "Análisis de la posición ideológica del gobierno ecuatoriano en el contexto de la movilización indígena antiextractiva". Cuadernos del CENDES, No 91: 65-91.

VEGA, Fernando. 2014. "El Buen Vivir-Sumak Kawsay en la Constitución y en el PNBV 2013-2017 del Ecuador". OBETS. Revista de Ciencias Sociales, Vol. 9, N 1: 167-194.

VIOLA RECASENS, Andreu. 2014. "Discursos «pachamamistas» versus políticas desarrollistas: el debate sobre el sumak kawsay en los Andes". Íconos. Revista de Ciencias Sociales, $\mathrm{N}^{\circ}$ 48: 55-72. 
WALSH, Catherine. 2012. Interculturalidad crítica y (de)colonialidad. Ensayos desde Abya Yala. Quito: Abya Yala.

. 2007. "¿Son posibles unas ciencias sociales/culturales otras? Reflexiones en torno a las epistemologías decoloniales". Nómadas, $\mathrm{N}^{\circ} 26$ : 102-113.

. 2009. "Interculturalidad, decolonialidad y el buen vivir". En: Interculturalidad, Estado, sociedad. Luchas (de) coloniales de nuestra época. Quito: Universidad Andina Simón Bolívar, Ediciones Abya-Yala, pp. 213-23.

YOUNG, Iris Marion. 1990. Justice and the politics of difference. Princeton: Princeton University Press.

YRIGOYEN, Raquel. 2004. "Pluralismo jurídico, derecho indígena y jurisdicción especial en los países andinos". El otro derecho, $\mathrm{N}^{\circ}$ 30: 171-195. 


\section{EL BUEN VIVIR COMO DISCURSO CONTRAHEGEMÓNICO. POSTDESARROLLO, INDIGENISMO Y NATURALEZA DESDE LA VISIÓN ANDINA}

\section{Resumen}

En el presente trabajo queremos ahondar en la noción "Buen Vivir", entendiéndolo como un concepto con enorme potencia contrahegemónica. Para ello, indagaremos en su fuerte crítica a la modernidad eurocéntrica, en concreto, a las ideas de "progreso" y "desarrollo" provenientes del Norte Global. Analizaremos igualmente cómo algunos elementos de la cosmovisión indígena andina han contribuido notablemente a la construcción de discursos y praxis que han intentado salirse del paradigma desarrollista y extractivista. Consideraremos, por ende, que el "Buen Vivir", cuya presencia puede rastrearse incluso en geografías indígenas no andinas, ha constituido un contrapunto epistémico y ético-político al desarrollismo, al productivismo y al neoliberalismo.

Palabras clave: Buen Vivir, Desarrollismo, Productivismo, Extractivismo, Neoliberalismo.

\section{BUEN VIVIR AS A COUNTER- HEGEMONIC DISCOURSE. POST-DEVELOPMENT, INDIGENISM AND THE NATURE FROM THE ANDEAN POINT OF VIEW}

\begin{abstract}
In this article we delve into the notion "Good Living", understanding it as a concept with immense counterhegemonic power. We investigate its compelling criticism of Eurocentric modernity, specifically the ideas of "progress" and "development" deriving from the Global North. We also analyze how some elements of the indigenous Andean worldview have contributed significantly to the construction of discourses and praxis that have tried to bypass of the developmentalist and extractivist paradigm. We therefore consider that "Good Living," whose presence can be traced even in non-Andean indigenous geographies, has constituted an epistemic and ethical-political counterpoint to developmentalism, productivism and neoliberalism.
\end{abstract}

Keywords: Good living, developmentalism, productivism, extractivism, neoliberalism. 


\title{
BEM VIVER COMO DISCURSO \\ CONTRA-HEGEMÔNICO. \\ PÓS-DESENVOLVIMENTO, \\ INDIGENISMO E NATUREZA \\ DESDE A VISÃO ANDINA
}

\begin{abstract}
Resumo
No presente trabalho, nós queremos aprofundar a noção de "Bom Viver", entendendo-a como um conceito com enorme poder contra-hegemônico. Para fazer isso, nós investigaremos as suas fortes críticas à modernidade eurocêntrica, especificamente às ideias de "progresso" e "desenvolvimento" do Norte Global. Nós analisaremos também como alguns elementos da visão de mundo indígena andina contribuíram significativamente para a construção de discursos e práxis que tentaram sair do paradigma desenvolvimentista e extrativista. Consideraremos, portanto, que o "Bom Viver", cuja presença pode ser rastreada mesmo em geografias indígenas não andinas, constituiu um contraponto epistêmico e ético-político ao desenvolvimentismo, produtivismo e neoliberalismo.
\end{abstract}

Palavras-chave: Bom viver, Desenvolvimentismo, Produtivismo, Extrativismo, Neoliberalismo. 